\title{
Current behavioral, socioeconomic and demographic determinants of lifetime HIV testing among African Americans in the deep south
}

\author{
Kemi Ogunsina*1, Luz A. Padilla ${ }^{2}$, Jazmyne V. Simmons ${ }^{3}$, Gerald McGwin ${ }^{2}$ \\ ${ }^{1}$ Department of Epidemiology University of Miami, FL, United States \\ ${ }^{2}$ Department Epidemiology, University of Alabama at Birmingham, Alabama, United States \\ ${ }^{3}$ Department of Communication studies, University of Miami, Florida, United States
}

Received: July 16, 2018

DOI: $10.5430 /$ jer.v5n $1 \mathrm{p} 28$
Accepted: October 21, 2018

URL: https://doi.org/10.5430/jer.v5n1p28
Online Published: December 28, 2018

\begin{abstract}
Objective: The Southern region of the United States (US) experiences higher HIV related disparities, majority of new HIV infections are transmitted by individuals who are unaware of their status. African Americans constitute $44 \%$ of HIV diagnosis in the US, and African American gay and bisexual men accounted for the largest number of new HIV diagnosis in 2016.

Methods: Data from nine southern states in the Behavioral Risk Factor Surveillance System (BRFSS) 2016 was analyzed using logistic regression.

Results: We found Individuals less likely to test for HIV included: heterosexuals, married individuals, living in a nonMetropolitan Statistical Area (MSA), others (retirees, students and homemakers), older than 65 years and/or with less than high school education.

Conclusion: Amid finite resources, interventions for HIV testing among African Americans should focus more on these individuals who are less likely to be aware of their HIV status, further contributing to new HIV infections.
\end{abstract}

Key Words: African American, HIV testing, BRFSS, Deep south, HIV prevention, HIV awareness

\section{INTRODUCTION}

One of the major challenges of HIV prevention is lack of awareness of HIV status among individuals. ${ }^{[1]}$ Over the years (2011-2015) the African American community has experienced an $8 \%$ decrease in new HIV diagnoses ${ }^{[1]}$ however the burden of HIV remains disproportionately higher especially among African Americans living in the Deep South region of the United States (US). ${ }^{[2]}$ According to the Centers for Disease Control and Prevention (CDC), the South makes up $38 \%$ of the entire US population, but accounts for $45 \%$ of all people living with HIV, and 53\% of all new HIV di- agnoses in 2016. ${ }^{[1,3,4]}$ Despite recent progress and decline in overall incidence of HIV in the US, Southern states bear the greatest brunt of the illness. ${ }^{[4]}$ The rates of new HIV diagnoses per 100,000 people in 2016 were 16.8 in the South compared to 11.2 in the Northeast, 10.2 in the West and 7.5 in the Midwest. ${ }^{[4]}$ People living with HIV in the South are less likely to be aware of their status when compared to people living in other regions. ${ }^{[5]}$ Studies have shown that the majority of new HIV infections in the US are transmitted by people who were unaware of their HIV status. ${ }^{[1,6,7]}$ Disproportionately affected are nine priority states in the

*Correspondence: Kemi Ogunsina; Email: oio10@miami.edu; Address: Department of Epidemiology, University of Miami, FLorida, United States. 
Deep South namely: Alabama, Florida, Georgia, Louisiana, Mississippi, North Carolina, South Carolina, Tennessee, and Texas. ${ }^{[4,8,9]}$ A study of key HIV prevention and care indicators show that Southern states are behind other regions in terms of HIV prevention and treatment. ${ }^{[4]}$ The HIV epidemic in the South is larger and more geographically dispersed than in other regions, ${ }^{[4]}$ according to the CDC, African American men having sex with men (MSM) made up the highest proportion of individuals diagnosed with HIV in 2016, with over 10,000 newly diagnosed. ${ }^{[6]}$ Among women in the US, African American heterosexual women had the highest with over 4 times the number of newly diagnosed HIV cases seen among Whites or Latino women in 2016. ${ }^{[6,10]}$ Disparities exist in each race/ethnic group among men having sex with men (MSM); reports show that only 54\% of black MSM are aware of their HIV status compared to $86 \%$ of white MSM and $63 \%$ of Hispanic MSM, ${ }^{[4]}$ thus posing a challenge. African Americans are more likely to be diagnosed late due to social and economic factors limiting access to health care and resulting in delayed treatment. ${ }^{[1-13]}$ Recent studies report that among African Americans, women are more likely to get screened for HIV than men due to gender differences in predictors of HIV testing such as age, sexual risk behavior, and negative HIV testing attitude. ${ }^{[14]}$ An intricate set of socioeconomic, behavioral and demographic factors underlie HIV risk within the African American population. ${ }^{[4,15]}$ Frequently reported factors are lack of health insurance, insufficient knowledge/low educational levels, social stigma, and rural/urban residence. ${ }^{[4,16,17]}$ Another reported factor responsible for the increased cases of HIV among African American women is the limited partner availability, ${ }^{[18]}$ partly due to high rates of incarceration, among young African American men. ${ }^{[3]}$ Incarceration is said to reduce the number of available male sexual partners within the communities, increasing the likelihood of women having multiple sexual partners and concurrent relationships, therefore increasing the spread of HIV. ${ }^{[12,13,18]}$ Testing for HIV provides the benefits of early diagnosis and treatment, which reduces the risk of transmission and the overall long-term cost of disease management for persons living with HIV (PLWH). ${ }^{[19]}$ Additionally, early testing leads to awareness and individuals who are aware of their HIV status are more likely to avoid risky practices that can lead them to infect others. ${ }^{[20]}$ Therefore, testing is paramount in reducing the spread of HIV infections. In this study, we examine current HIV testing prevalence, behavioral, socioeconomic, and demographic characteristics of African Americans who test for HIV in the US deep South. Additionally, we examined the likelihood of testing for HIV by gender based on a priori hypothesis, as gender differences plays a critical role in planning HIV prevention interven-

Published by Sciedu Press tions. $^{[21]}$ Findings from this study can assist state health services, policy makers and program planners in developing strategies to properly target HIV education, awareness and testing in the South, thereby reducing associated disparities.

\section{Methods}

\subsection{Sample selection}

A cross-sectional analysis was conducted on 14,558 African American men and women aged 18 to 80 years from nine priority states with the highest rates of new HIV diagnoses in the South. Data were obtained from the CDC website for the 2016 Behavioral Risk Factor Surveillance System (BRFSS) for the following states: Alabama, Florida, Georgia, Louisiana, Mississippi, North Carolina, South Carolina, Tennessee, and Texas. ${ }^{[2,4]}$

\subsection{Outcome}

The dependent variable of interest was ever been tested for HIV measured by the BRFSS question: "Have you ever been tested for HIV?" The independent variables of interest consist of behavioral, socioeconomic and demographic characteristics, such as age, gender, marital status, health insurance, sexual orientation, HIV risk behavior(s), Metropolitan Statistical Area (MSA), inability to access medical healthcare due to cost in the past 12 months, time since last routine health checkup, education, employment, income, and home ownership (i.e. whether the individual rented or owned their home).

\subsection{Variables categories}

Variables from the BRFSS data were further categorized as follows: Annual household income was categorized into three levels $<35,000,35,000-74,000$ and $>75,000$ to represent lower, middle and upper-income groups based on the American Enterprise Institute (AEI) revised income categories US census bureau 2014. Employment was categorized into employed, which consisted of private and public-sector workers; and unemployed, which consisted of individuals who were out of a job or unable to work at the time of the survey. Participants who identified as homemakers, students or retirees were categorized as other. Marital status was categorized as married/cohabiting, divorced/separated, never married, and widowed. Sexual orientation was classified as lesbian, gay or bisexual (LGB) and heterosexual. Education was categorized as some high school or less, high school graduates, some college, and college graduate. Health care access was treated as a binary variable reflecting a participant's response to the question "unable to access health care in the past 12 months due to cost?", HIV risk behavior(s) was treated as binary variable, based on whether an individual answered yes to one or more of the following risky behaviors: 
intravenous drug use in the past year, treated for sexually transmitted or venereal disease in the past year, received or given money or drugs in exchange for sex in the past year, had anal sex without a condom in the past year, or had four or more sexual partners in the past year.

\subsection{Statistical analysis}

Chi-square tests were used to compare specific behavioral, social and demographic characteristics between individuals who had ever tested for HIV, never tested for HIV, and those who refused or/did not know whether they had ever been tested for HIV. Logistic regression was used to estimate unadjusted odds ratios (ORs), and 95\% confidence interval (CI), comparing those who responded either yes or no to ever tested for HIV with respect to behavioral, social and demographic characteristics. Three sets of adjusted logistic regression models were run: (1) adjusting for all significant co-variables from the unadjusted analysis; (2) adjusting for variables based on literature reviews and knowledge of predictors of HIV testing; (3) testing for the presence of interaction between gender and age and risky HIV behavior Individuals with missing data for the dependent variable HIV test, were less than $1 \%$ of the data. The variable sexual orientation had $62 \%$ of missing data, though those with missing and non-missing data were not significantly different. All statistical analysis took into account the BRFSS sampling weights. $P$-values of .05 (two-sided) were considered statistically significant. All statistical analyses was conducted using SAS 9.4 (SAS Institute Inc. NC, USA).

\section{Results}

Overall, over half $(51.4 \%)$ of the participants had ever received an HIV test. With respect to age, the age groups (18-24 years and $\geq 65$ years) were associated with a lower rate of HIV testing. A larger proportion of widowed individuals $(11.3 \%)$ was observed among those who had never tested for HIV compared to those who had ever tested for HIV (4.3\%), $p$-value < .0001. HIV risky sexual behavior was lower among those who never tested for HIV (4.70\%), compared to those who had tested for HIV (10.4\%), $p$-value $<.0001$. A higher proportion of individuals who had health insurance $(84.6 \%)$ reported never testing for HIV compared to those who had tested for HIV $(81.7 \%), p$-value $<.0205$. A higher proportion never tested for HIV lived in non-MSA areas $(22.2 \%)$ compared to those who tested for HIV (16.3\%), $p$-value $<.0037$. A higher proportion of individuals who had some high school or less $(19.8 \%)$ or had completed high school $(36.9 \%)$ education, reported never testing for HIV compared to those who tested for HIV $13.9 \%$ and $29.7 \%$ respectively, $p$-value $<.001$. Among individuals who reported their employment status as student, homemakers or retired, a higher proportion had never been tested for HIV (38.1\%) than ever tested for HIV (13.3\%), $p$-value < .0001. Those never tested for HIV reported lower household income less than $\$ 35,000$, when compared with those ever tested for HIV, $p$-value .0074. There was no significant difference in characteristics of individuals by gender or by health care cost among those who never tested compared to those who reported ever tested for HIV (see Table 1).

Effect modification was noted for all levels of age (see Table 2). For example, compared with females 65 years and older, the odds ratio for HIV testing among 18 to 24-year-old African American females was 4.38 (2.89 - 6.65) but rose to 13.5 (10.4 - 18.7) for 25 to 44-year-old African American females.

The age groups $18-24$ years, $25-44$ years, $45-64$ years were more likely to have received a HIV test compared to individuals 65 years or older (OR 2.51, 95\% CI: $1.92-3.28$, OR $8.24,95 \%$ CI: $6.70-10.1$, OR $3.51,95 \%$ CI: $2.88-4.26$, respectively); the group who was most likely to get tested were those 25-44 years of age (see Table 3). Divorced or separated individuals were more likely than married individuals to test for HIV (OR 1.36, 95\% CI: 1.15 - 1.63), while widowed individuals were less likely to have ever tested for HIV than married individuals (OR 0.37, 95\% CI: $0.29-0.48$ ). Heterosexuals were less likely to have tested for HIV than individuals who were LGB (OR 0.33, 95\% CI: $0.15-0.74$ ). Those with some college (OR 1.73, 95\% CI: $1.39-2.15$ ), and college graduates (OR 2.10, 95\% CI: 1.69 - 2.61) were more likely to have tested for HIV compared to individuals with some high school education or less. Unemployed individuals (OR 0.81, 95\% CI: $0.68-0.95$ ), and others (students, home makers and retired) (OR 0.32, 95\% CI: $0.27-0.38$ ) were less likely to test for HIV than employed individuals. Those who reported higher household income \$35,000-\$75,000 and greater than $\$ 75,000$ were more likely to screen for HIV than those reporting incomes less than $\$ 35,000$ (OR1.31, 95\% CI: 1.10 - 1.57, OR 1.49, 95\% CI: 1.19 - 1.87, respectively). Individuals having risky sexual behavior were more likely to screen for HIV than individuals with no risky sexual behavior (OR 2.43, 95\% CI: 1.85 - 3.21). Individuals living in an MSA were more likely to have tested for HIV than those living in a non- MSA (OR 1.46, 95\% CI: 1.18 - 1.80). Having health insurance was not significantly associated with lifetime testing for HIV. 
Table 1. Baseline characteristics of participants from nine priority states with high rates of HIV in the south (BRFSS 2016)

\begin{tabular}{|c|c|c|c|c|}
\hline & $\begin{array}{l}\text { Ever Received HIV test } \\
\mathrm{N}=7,488(51.4 \%)\end{array}$ & $\begin{array}{l}\text { Never Received HIV test } \\
\mathrm{N}=\mathbf{6 , 6 8 6}(45.9 \%)\end{array}$ & $\begin{array}{l}\text { Don't Know/ Refused } \\
\text { N = } 384(2.64 \%)\end{array}$ & $P$ value \\
\hline Age group & & & & $<.0001$ \\
\hline $18-24$ & 517 (12.9) & 417 (18.6) & $14(6.79)$ & \\
\hline $25-44$ & 2,833 (47.2) & 799 (20.8) & 43 (18.9) & \\
\hline $45-64$ & 3,068 (32.4) & 2,564 (33.5) & 148 (34.4) & \\
\hline$\geq 65$ & $1,070(7.47)$ & $2,906(27.1)$ & 179 (39.9) & \\
\hline Gender & & & & .8167 \\
\hline Male & $2,882(44.5)$ & $2,261(45.1)$ & $140(48.6)$ & \\
\hline Female & $4,606(55.5)$ & 4,424 (54.9) & $244(51.4)$ & \\
\hline Marital status & & & & $<.0001$ \\
\hline Married/cohabit & 2,544 (35.9) & $2,444(37.1)$ & $134(38.4)$ & \\
\hline Never married & 2,553 (40.3) & 1,575 (36.6) & $72(24.1)$ & \\
\hline Divorced/Separated & 1,799 (19.8) & $1,331(15.0)$ & $90(18.4)$ & \\
\hline Widowed & 549 (4.08) & $1,297(11.3)$ & $84(19.1)$ & \\
\hline \multicolumn{5}{|l|}{ Sexual Orientation } \\
\hline $\mathrm{LGB}^{\#}$ & $76(6.07)$ & $25(1.73)$ & & .0003 \\
\hline Heterosexual/straight & 2,126 (94.9) & 2,129 (98.3) & & \\
\hline Education & & & & $<.0001$ \\
\hline Some high school or less & $882(13.9)$ & 1,185 (19.8) & $67(21.6)$ & \\
\hline High Sch. Graduate & 2,447 (29.7) & 2,569 (36.9) & 125 (36.9) & \\
\hline Some College $e^{¥}$ & $2,172(34.6)$ & $1,505(28.5)$ & $105(30.1)$ & \\
\hline College Graduate $^{\beta}$ & $1,970(21.9)$ & $1,405(14.8)$ & $87(11.4)$ & \\
\hline Employment & & & & $<.0001$ \\
\hline Employed & $4,110(62.2)$ & $2,264(44.0)$ & $126(38.4)$ & \\
\hline Unemployed & $1,789(20.5)$ & $1,494(18.0)$ & $91(12.2)$ & \\
\hline Others^ ${ }^{\wedge}$ & $1,589(17.3)$ & $2,928(38.1)$ & $167(49.5)$ & \\
\hline Household income & & & & .0074 \\
\hline$<35,000$ & 3,863 (52.7) & 3,499 (60.5) & $187(57.8)$ & \\
\hline $35,000-74,000$ & $1,710(28.6)$ & $1,228(25.0)$ & $57(22.6)$ & \\
\hline$\geq 75,000$ & $959(18.7)$ & $619(14.4)$ & $42(19.5)$ & \\
\hline Home status & & & & $<0.0001$ \\
\hline Own home & 3,762 (50.7) & $4,316(57.7)$ & $252(66.1)$ & \\
\hline Rent home & $3,168(42.3)$ & $1,837(31.6)$ & $108(28.5)$ & \\
\hline Others $\wedge$ & $525(7.01)$ & 479 (10.7) & $22(5.45)$ & \\
\hline Health care access due to cost & & & & .1321 \\
\hline Yes & $1,486(21.0)$ & $961(17.3)$ & $52(18.7)$ & \\
\hline No & $5,973(78.9)$ & $5,868(82.7)$ & 327 (81.3) & \\
\hline Health Insurance & & & & .0205 \\
\hline Yes & 6,316 (81.7) & $5,900(84.6)$ & 347 (89.4) & \\
\hline No & $1,138(18.3)$ & $754(15.4)$ & $35(10.6)$ & \\
\hline Medical Check up & & & & .0214 \\
\hline Never & $33(0.69)$ & $36(1.50)$ & $3(1.31)$ & \\
\hline$<12$ months & $6,121(80.0)$ & $5,545(76.4)$ & $322(81.3)$ & \\
\hline $1-2$ years & $692(10.6)$ & $523(10.1)$ & $29(9.48)$ & \\
\hline > 2years & $553(8.8)$ & $490(12.0)$ & $21(7.96)$ & \\
\hline HIV risk behavior(s) & & & & $<0.0001$ \\
\hline Yes & $621(10.8)$ & $210(4.70)$ & $17(5.4)$ & \\
\hline No & 6,789 (89.2) & 6,435 (95.3) & 334 (94.6) & \\
\hline MSA residence** & & & & .0037 \\
\hline MSA & $1,885(83.7)$ & $2,307(77.8)$ & $121(82.5)$ & \\
\hline Not MSA & 886 (16.3) & 1,468 (22.2) & 85 (17.5) & \\
\hline State* & & & & $<.0117$ \\
\hline Alabama & $861(6.75)$ & 809 (8.07) & $55(9.13)$ & \\
\hline Florida & $1,945(18.1)$ & $1,257(15.3)$ & $71(12.4)$ & \\
\hline Georgia & 724 (17.9) & $525(17.2)$ & 25 (11.6) & \\
\hline Louisiana & 509 (8.22) & 585 (8.17) & $22(6.01)$ & \\
\hline Mississippi & $873(6.08)$ & 844 (6.46) & $72(9.61)$ & \\
\hline North Carolina & 625 (11.8) & 533 (13.8) & $31(10.2)$ & \\
\hline South Carolina & 1,231 (6.87) & 1,410 (8.11) & $69(5.22)$ & \\
\hline Tennessee & 332 (6.46) & 318 (5.94) & $20(4.86)$ & \\
\hline Texas & 388 (17.8) & 405 (16.9) & 19 (30.9) & \\
\hline
\end{tabular}

Mliving in a group home, staying with friends or family without paying rent, *Nine priority states with high HIV rates in the Deep South, Bold is significant at $\boldsymbol{\alpha}=\mathbf{0 . 0 5}$ 
Table 2. Predictors of self-reported life time HIV testing stratified by gender among African Americans in 9 states in the South

\begin{tabular}{lll}
\hline Factors & $\begin{array}{l}\text { Female } \\
\text { Odds Ratio (95\% CI) }\end{array}$ & $\begin{array}{l}\text { Male } \\
\text { Odds Ratio (95\% CI) }\end{array}$ \\
\hline Age (years) & & \\
$\geq 65$ & Ref & Ref \\
$18-24$ & $4.38(2.89-6.65)$ & $1.32(0.91-1.91)$ \\
$25-44$ & $13.5(10.4-18.7)$ & $4.62(3.43-6.23)$ \\
$45-64$ & $4.03(3.06-5.29)$ & $2.97(2.31-3.95)$ \\
HIV risk & & \\
behavior(s) & & \\
No & Ref & Ref \\
Yes & $0.33(0.22-0.51)$ & $0.46(0.32-0.67)$ \\
\hline
\end{tabular}

Following adjustment, the age group $18-24$ years (AOR: 2.06, 95\% CI: 0.87-4.87), was no longer significant, while age groups 25 - 44 years, 45 - 64 years remained significantly more likely than 65 years or older to test for HIV (AOR 6.47, 95\% CI: 4.13-10.1, and AOR 2.70, 95\% CI: 1.93-3.77, respectively). Being divorced/separated remained significantly more likely to test for HIV than married /cohabiting (AOR 1.67, 95\% CI: 1.20-2.32). Having a higher education, some college or college graduates were no longer significantly associated with testing for HIV than less than high school education (AOR 1.16, 95\% CI: 0.81-1.68, AOR 1.01, 95\% CI: 0.66-1.53, respectively). Students, homemakers or retired individuals remained significantly less likely than employed individuals to test for HIV (AOR 0.62, 95\% CI: 0.44-0.87). Heterosexuals remained significantly less likely to test for HIV than LGB (AOR 0.20, 95\% CI: 0.04 $0.98)$. Individuals with annual household income greater than $\$ 75,000$ remained significantly more likely to screen for HIV than those with annual household income less than $\$ 35,000$ (AOR 1.92, 95\% CI: 1.23-3.02). Engaging in risky sexual behavior was no longer significantly associated with testing for HIV (AOR 1.79, 95\% CI: 0.98-3.27), than not engaging in risky sexual behaviors. Living in an MSA region was no longer significantly associated with testing for HIV (AOR 1.26 95\% CI: 0.96-1.66), than living in a non-MSA. In a logistic regression model with an interaction between gender and age, was statistically significant. Divorced/separated individuals remained significantly more likely to test for HIV than married /cohabiting (AOR 1.71, 95\% CI: 1.22-2.38). Students, homemakers or retired individuals remained significantly less likely than employed individuals to test for HIV (AOR 0.61, 95\% CI: 0.44-0.8). Heterosexuals remained significantly less likely to test for HIV than LGB (AOR 0.19, 95\% CI: 0.04-0.84). Individuals who have never had a checkup were less likely to test for HIV (AOR 0.01, 95\% 0.00-0.07). While individuals with household income greater than $\$ 75,000$ remained more likely to screen for HIV than those with annual household income less than \$35,000 (AOR 1.92, 95\% CI: $1.23-3.02)$.

\section{Discussion}

Factors associated with lower odds of HIV testing among African Americans living in the Deep South included age 65 years and older, heterosexual identity, never received a medical check-up reporting employment as others (student, homemakers or retiree). Other factors associated with higher odds of testing is having household income $\$ 75,000$ or more. African Americans in the older age groups may have a low self-perceived risk of HIV, contributing to the lower likelihood of HIV testing observed in this age group. ${ }^{[21]}$ Other reasons may be because majority of older adults in the AA population run female headed and grandparent headed households with minimal resources, experiencing age related disabilities that make it hard to engage in activities of daily living, while catering to the needs of their household. ${ }^{[22]}$ This may cause them to experience financial challenges and transportation barriers with poor access to HIV testing. Additionally, studies have shown that states in the Deep South suffer challenges of fewer HIV care providers, poor transportation systems, and access to HIV testing, lessening the chances of HIV testing. ${ }^{[2,23]}$ However, those age 25-44 had the highest rates of testing. Individuals who have never had a medical checkup were less likely to have tested for HIV. Petroll et al and other similar studies have reported that majority of HIV testing often occurs as part of a routine care or based on recommendation by the patient's primary physician. ${ }^{[12,24-26]}$ African Americans with higher levels of income were more likely to test for HIV than those with lower income. This is supported by recent studies by the CDC that listed low income as a risk factor for HIV among African Americans. ${ }^{[1]}$ Higher income individuals may have greater access to health care. While studies have shown that low income young African American men have poor access to health services with limited or no health insurance coverage. ${ }^{[27]}$ Other reasons could be that low income individuals may have unstable housing which has been found to be associated with lower likelihood of obtaining a HIV test. ${ }^{[28]}$ They also have been shown by studies to express concerns about access to affordable treatment if they test positive. ${ }^{[29]}$

Higher level of education was also a significant predictor of lifetime HIV testing among African Americans, as individuals with some college or complete college education were more likely to have tested for HIV compared to those with high school or less than high school education Findings from other studies have showed that HIV testing rates increase with increased level of education. ${ }^{[30,31]}$ However, in our 
study, this finding was not consistent after adjusting for other characteristics. Individuals who reported their employment status as retired, homemakers or students, were less likely to have ever been tested for HIV. This group consisted of individuals who are either very young (18 to 25 years), or older than 65 years and females. The lower likelihood of testing for HIV among this group may be cost related due to their lower earning power as students, homemakers or retirees. Additionally, they may prefer testing in private clinics than during free mobile street campaigns, and in government facilities due to privacy reasons or mistrust of government facilities. ${ }^{[32]}$ Although, it may seem that these groups may have the most available time to pursue health care and HIV testing, a combination of any of these factors will pose a challenge to them testing for HIV. Additionally, lack of knowledge regarding available services to persons living with HIV/AIDS (PLWHA) may also contribute to reduced HIV testing rates in the Deep South. ${ }^{[30]}$ As individuals may fear an HIV-positive diagnosis will result in terminal illness due to lack of available resources, such as medication assistance programs. ${ }^{[33]}$ Heterosexuals are less likely to test for HIV than LGBs, this could be due to low perceived risk of contracting HIV and avoidance of HIV testing due to the cultural stigma attached to it. ${ }^{[23]}$ Some communities have been observed to respond to the HIV epidemic as though it were a disease of LGB individuals. ${ }^{[34]}$ Moreover, across all sexual orientations, age groups and socioeconomic levels, the criminalization of HIV further exacerbates HIV-related stigma. ${ }^{[35]}$ A study by Raj. A. et al. in 2012 showed that HIV health disparities is increasing among heterosexual black males while national prevention efforts within the African American communities are being focused primarily on MSM. ${ }^{[36]}$

HIV-related cultural stigma may also be a reason for lower likelihood of testing among married individuals who would not want to appear as being unfaithful. In the past, African American churches framed HIV as a moral issue rather than a health issue part of which brought about HIV stigma within African American communities. ${ }^{[23]}$ Moreover, Laws against non-disclosure are heavily concentrated and enforced in the South. ${ }^{[35]}$ Consequently, individuals might be more reluctant to test for HIV as knowledge of one's status creates the responsibility to disclose to sexual partners. Individuals who had never had a medical check-up, or who do not go for yearly medical checkup are less likely to have ever had a HIV test. This group may be individuals who do not have health insurance, or do not feel their health is at risk, or may be experiencing challenges due to cost and access to HIV testing, or even lacking knowledge about HIV testing. This group would likely not be influenced by physicians to get a HIV test. Studies have shown that physician influence is a major driving force for HIV testing among African Americans. ${ }^{[25]}$ Published by Sciedu Press
Not owning or able to rent a home, was associated with lower likelihood of ever testing for HIV. However, after adjusting for other co-variables, this finding was no longer significant. The availability and sustainability of free HIV counseling and testing services at churches and outreach centers, in the South could mitigate the fear, stigma, access and financial challenges of getting tested. ${ }^{[23]}$ Furthermore, the use of home-based HIV rapid testing (HBHRT) with the assistance of community health workers appears to be a promising strategy for increasing HIV testing among individuals of lowsocioeconomic status in the South. ${ }^{[33]}$ Additional strategies aimed at promoting HIV testing should target specific groups shown to have less likelihood of testing for HIV such as the elderly, those who have lower income, married individuals, heterosexuals and individuals who are unemployed, reporting employment as homemakers, students or retired. Integrated counseling and testing centers (ICTCs) and information, education and communication (IECs) initiatives, such as the Fast-Track Cities in Miami-Dade County ${ }^{[32]}$ are present in southern states. However, as asserted by researchers, there is a need for broader dissemination of such effective strategies. ${ }^{[31]}$ Furthermore, potentially adding to the lack of testing in the Deep South, is the lack of testing within emergency rooms. ${ }^{[27]}$ An evaluation by the Southern HIV/AIDS Strategy Initiative found that some emergency rooms only provided testing to patients they presumed to be at high risk. Therefore, potentially overlooking the populations identified at risk within this study (e.g. homemakers). Aggressive efforts such as media campaigns and distribution of IEC materials specifically designed to target low income individuals to increase awareness and reinforce knowledge on repeat HIV testing for sexually active individuals is needed. Radio jingles and advertisements on public transport systems through the screens or posters should lay emphasis on the need for individuals to attend yearly general check-up with primary physicians. Missed opportunities can be avoided by primary physicians making sure they offer HIV testing to clients especially those at higher risk for HIV who present in the clinic for other reasons. Provision of HIV testing through trusted organizations like the church at a time that is convenient and a location that is accessible should also be put in place. Long term interventions should aim at improving transportation systems to health facilities and including comprehensive sex education in school curricular, thereby providing access to STD and HIV prevention and increasing health knowledge. More studies are required to examine the presence of low perceived risk of HIV among heterosexuals and the married population who currently exhibit a lower likelihood of testing for HIV. More studies are required to understand the current situation of stigma regarding HIV and current perception and trust of government owned health facilities among African American communities. 
Table 3. Association between behavioral and socio demographic factors and self-reported life time HIV testing among African Americans in 9 states in the South

\begin{tabular}{|c|c|c|c|}
\hline Factors & $\begin{array}{l}\text { Crude } \\
\text { Odds Ratio (95\% CI) }\end{array}$ & $\begin{array}{l}\text { Adjusted } \\
\text { Odds Ratio }^{\mathrm{a}}(95 \% \mathrm{CI})\end{array}$ & $\begin{array}{l}\text { Adjusted } \\
\text { Odds Ratiob }^{b}(95 \% \text { CI) }\end{array}$ \\
\hline \multicolumn{4}{|l|}{ Age (years) } \\
\hline$\geq 65$ & Ref & Ref & \\
\hline $18-24$ & $2.51(1.92-3.28)$ & $2.06(0.87-4.87)$ & \\
\hline $25-44$ & $8.24(6.70-10.1)$ & $6.47(4.13-10.1)$ & \\
\hline $45-64$ & $3.51(2.88-4.26)$ & $2.70(1.93-3.77)$ & \\
\hline \multicolumn{4}{|l|}{ Gender } \\
\hline Male & Ref & Ref & \\
\hline Female & $1.03(0.90-1.18)$ & $0.84(0.64-1.10)$ & \\
\hline \multicolumn{4}{|l|}{ Marital status } \\
\hline Married/cohabit & Ref & Ref & \\
\hline Never married & $1.14(0.97-1.34)$ & $1.17(0.84-1.63)$ & $1.21(0.86-1.70)$ \\
\hline Divorced/Separated & $1.36(1.15-1.63)$ & $1.67(1.20-2.32)$ & $1.71(1.22-2.38)$ \\
\hline Widowed & $0.37(0.29-0.48)$ & $0.81(0.55-1.19)$ & $0.85(0.57-1.26)$ \\
\hline \multicolumn{4}{|l|}{ Sexual Orientation } \\
\hline $\mathrm{LGB}^{\#}$ & Ref & Ref & Ref \\
\hline Heterosexual/straight & $0.33(0.15-0.74)$ & $0.20(0.04-0.98)$ & $0.19(0.04-0.84)$ \\
\hline \multicolumn{4}{|l|}{ Education } \\
\hline Some high school or less & Ref & Ref & Ref \\
\hline High Sch. Graduate & $1.15(0.93-1.41)$ & $0.82(0.58-1.16)$ & $0.83(0.58-1.18)$ \\
\hline Some College ${ }^{¥}$ & $1.73(1.39-2.15)$ & $1.16(0.81-1.68)$ & $1.14(0.78-1.65)$ \\
\hline College Graduate $^{\beta}$ & $2.10(1.69-2.61)$ & $1.01(0.66-1.53)$ & $0.96(0.63-1.48)$ \\
\hline \multicolumn{4}{|l|}{ Employment } \\
\hline Employed & Ref & Ref & Ref \\
\hline Unemployed & $0.81(0.68-0.95)$ & $1.05(0.74-1.47)$ & $1.09(0.78-1.52)$ \\
\hline Others^ & $0.32(0.27-0.38)$ & $0.62(0.44-0.87)$ & $0.61(0.44-0.85)$ \\
\hline \multicolumn{4}{|l|}{ Household income } \\
\hline$<35,000$ & Ref & Ref & \\
\hline $35,000-74,000$ & $1.31(1.10-1.57)$ & $1.10(0.78-1.54)$ & $1.16(0.83-1.61)$ \\
\hline$\geq 75,000$ & $1.49(1.19-1.87)$ & $1.92(1.23-3.02)$ & $2.05(1.32-3.21)$ \\
\hline \multicolumn{4}{|l|}{ Home status } \\
\hline Own home & Ref & Ref & Ref \\
\hline Rent home & $1.52(1.32-1.76)$ & $1.22(0.90-1.66)$ & $1.23(0.91-1.66)$ \\
\hline Others $\wedge \wedge$ & $0.75(0.59-0.95)$ & $0.74(0.42-1.31)$ & $0.73(0.40-1.32)$ \\
\hline \multicolumn{4}{|l|}{ Health Insurance } \\
\hline No & Ref & Ref & Ref \\
\hline Yes & $0.89(0.71-1.11)$ & $1.29(0.83-2.00)$ & $1.23(0.78-1.93)$ \\
\hline \multicolumn{4}{|l|}{ Medical Check up } \\
\hline$>2$ years & Ref & Ref & Ref \\
\hline Never & $0.63(0.25-1.61)$ & $0.01(0.00-0.08)$ & $0.01(0.00-0.07)$ \\
\hline$<12$ months & $1.43(1.14-1.81)$ & $1.54(0.94-2.52)$ & $1.53(0.95-2.46)$ \\
\hline 1 - 2 years & $1.44(1.05-1.97)$ & $1.33(0.72-2.25)$ & $1.40(0.77-2.52)$ \\
\hline \multicolumn{4}{|l|}{ HIV risk behavior(s) } \\
\hline No & Ref & Ref & Ref \\
\hline Yes & $2.43(1.85-3.21)$ & $1.79(0.98-3.27)$ & $1.79(0.98-3.30)$ \\
\hline \multicolumn{4}{|l|}{ MSA residence** } \\
\hline Not MSA & Ref & Ref & Ref \\
\hline MSA & $1.46(1.18-1.80)$ & $1.26(0.96-1.66)$ & $1.27(0.96-1.69)$ \\
\hline
\end{tabular}


Strengths to this study include the large sample size of African Americans across 9 Deep South states driving the HIV epidemic in the US, the random sampling method used for participants, and collection of data by trained personnel in the state health departments. Limitations to this study include the cross-sectional nature of the BRFSS data, not allowing for continued follow up of individuals behavior towards HIV testing, self-reported data which is vulnerable to recall bias, and possible variation in interpretation of questions by responders based on their understanding of the questions.

\section{CONFlicts of InTEREST Disclosure}

The authors declare that they have no competing interests.

\section{REFERENCES}

[1] CDC. HIV among African Americans. CDC Fact Sheet. 2018.

[2] Susan S. Reif DS, Elena W, et al. HIV/AIDS in the U.S. Deep South: Trends from 2008-2013. Southern HIV/AIDS Strategy Initiative. 2016.

[3] AVERT. HIV AND AIDS IN THE UNITED STATES OF AMERICA (USA). 2016. Available from: http: //www . avert.org/professionals/hiv-around-world /western-central-europe-north-america/usa.

[4] CDC. Living With HIV and Deaths, by Region. 2017. Available from: https://www.cdc.gov/hiv/statistics/overview/ge ographicdistribution.html. Accessed: 3/26/2018.

[5] CDC. Today's HIV/AIDS Epidemic. CDC Fact Sheet. 2016.

[6] CDC. HIV Diagnoses in the United States for the Most-Affected Subpopulations. 2016. Available from: https://www.cdc.gov/ hiv/group/gender/women/index.html. Accessed: 9/13/2018.

[7] Skarbinski J, Rosenberg E, Paz-Bailey G, et al. Human immunodeficiency virus transmission at each step of the care continuum in the United States. JAMA Internal Medicine. 2015; 175: 588-96. PMid:25706928. https://doi.org/10.1001/jamainternmed. 2014.8180

[8] CDC. CDC Factsheet; Trends in U.S HIV diagnosis, 2005 to 2014. 2015.

[9] Susan RC, Elena W. HIV in the U.S. Deep South. Research. Center for Health Policy \& Inequalities Research- Duke University- Duke University School of Law. 2017 April; 12.

[10] CDC. HIV in the southern United States. 2016. Available from: https://www.cdc.gov/hiv/pdf/policies/cdc-hiv-i n-the-south-issue-brief .pdf . Accessed: 9/13/2018.

[11] Valdiserri RO, Holtgrave DR. Ending America's HIV Epidemic: Why the National HIV/AIDS Strategy Still Matters. AIDS and behavior. 2018. PMid:29725789. https : //doi .org/10.1007/s104 61-018-2135-0

[12] Berkley-Patton J, Moore EW, Hawes SM, et al. Factors Related to HIV testing among an African American church-affiliated population. AIDS education and prevention: official publication of the International Society for AIDS Education. 2012; 24: 148-62. PMid:22468975. https://doi .org/10.1521/aeap. 2012.24.2 .148

[13] Mugavero MJ, Castellano C, Edelman D, et al. Late diagnosis of HIV infection: the role of age and sex. The American Journal of Medicine. 2007; 120: 370-3. PMid:17398235. https://doi.org/10.1016/ j.amjmed.2006.05.050

[14] Moore MP, Belgrave F. Gender Differencs in Predictors of HIV Testing Among African American Young Adults. Journal of Racial and Ethnic Health Disparities. 2018. https ://doi .org/10.1007/s4 0615-018-0513-y

[15] Millett GA, Crowley JS, Koh H, et al. A way forward: the National HIV/AIDS Strategy and reducing HIV incidence in the United States.
Journal of Acquired Immune Deficiency Syndromes (1999). 2010; 55(Suppl 2): S144-7.

[16] Benavides-Torres RA, Wall KM, Nunez R GM, et al. Factors Associated with Lifetime HIV Testing in Texas by Race/Ethnicity. The Open AIDS Journal. 2012; 6: 232-8. PMid:23115607. https : //doi.org/10.2174/1874613601206010232

[17] Nunn A, Yolken A, Cutler B, et al. Geography should not be destiny: focusing HIV/AIDS implementation research and programs on microepidemics in US neighborhoods. American Journal of Public Health. 2014; 104: 775-80. PMid:24716570. https : //doi.org/10.2105/AJPH. 2013.301864

[18] Newsome VR, Airhihenbuwa CO, Snipes SA. Educated and AtRisk: How the Shortage of Available Partners Influences HIV Risk for College-Educated African-American Women. Journal of the National Medical Association. 2018; 110: 219-30. PMid:29778123. https://doi.org/10.1016/j.jnma.2017.06.004

[19] Baggaley RF, Irvine MA, Leber W, et al. Cost-effectiveness of screening for HIV in primary care: a health economics modelling analysis. The Lancet HIV. 2017; 4: e465-e74. https : //doi .org/10.1016/ S2352-3018(17) 30123-6

[20] CDC. HIV Infection Risk, Prevention, and Testing Behaviors among Men Who Have Sex With Men. National HIV Behavioral Surveillance, 20 US Cities, 2014 HIV Surveillance Special Report 15. January 2016.

[21] Lindong I, Edwards L, Dennis S, et al. Similarities and Differences Matter: Considering the Influence of Gender on HIV Prevention Programs for Young Adults in an Urban HBCU. International Journal of Environmental Research and Public Health. 2017; 14. https://doi.org/10.3390/ijerph14020133

[22] James H. Johnson JSJA. U.S. Older adults: demographics, livingarrangements, and barriers to aging in place. 2017 May; 30.

[23] Stewart JM. A multi-level approach for promoting HIV testing within African American church settings. AIDS Patient Care and STDs. 2015; 29: 69-76. PMid:25682887. https://doi.org/10.1089/ apc. 2014.0160

[24] Nunn A, Eng W, Cornwall A, et al. African American patient experiences with a rapid HIV testing program in an urban public clinic. Journal of the National Medical Association. 2012; 104: 5-13. https://doi .org/10.1016/S0027-9684(15)30125-5

[25] Petroll AE, DiFranceisco W, McAuliffe TL, et al. HIV testing rates, testing locations, and healthcare utilization among urban AfricanAmerican men. Journal of Urban Health : Bulletin of the New York Academy of Medicine. 2009; 86: 119-31. PMid:19067176. https://doi.org/10.1007/s11524-008-9339-y

[26] Wong EY, Jordan WC, Malebranche DJ, et al. HIV testing practices among black primary care physicians in the United States. BMC Public Health. 2013; 13: 96. PMid:23375193. https ://doi .org/ 10.1186/1471-2458-13-96 
[27] MacQueen KM, Chen M, Jolly D, et al. HIV Testing Experience and Risk Behavior Among Sexually Active Black Young Adults: A CBPR-Based Study Using Respondent-Driven Sampling in Durham, North Carolina. American Journal of Community Psychology. 2015; 55: 433-43. PMid:25893817. https ://doi .org/10.1007/s104 64-015-9725-z

[28] Grieb SM, Davey-Rothwell M, Latkin CA. Housing stability, residential transience, and HIV testing among low-income urban African Americans. AIDS education and prevention: official publication of the International Society for AIDS Education. 2013; 25: 430-44. PMid:24059880. https://doi.org/10.1521/aeap. 2013.25.5 .430

[29] Wallace SA, McLellan-Lemal E, Harris MJ, et al. Why take an HIV test? Concerns, benefits, and strategies to promote HIV testing among low-income heterosexual African American young adults. Health education \& behavior : the official publication of the Society for Public Health Education. 2011; 38: 462-70. PMid:21464204. https://doi.org/10.1177/1090198110382501

[30] Onyeabor OS, Iriemenam N, Adekeye OA, et al. The effect of educational attainment on HIV testing among African Americans. Journal of Health Care for the Poor and Underserved. 2013; 24: 1247-56. PMid:23974395. https://doi.org/10.1353/hpu.2013.0113

[31] Painter JE, Wingood GM, DiClemente RJ, et al. College graduation reduces vulnerability to STIs/HIV among African-American young adult women. Women's health issues : official publication of the Jacobs Institute of Women's Health. 2012; 22: e303-10.

[32] Bohnert AS, Latkin CA. HIV testing and conspiracy beliefs regarding the origins of HIV among African Americans. AIDS patient care and STDs. 2009; 23: 759-63. PMid:19663716. https: //doi.org/10.1089/apc.2009.0061

[33] Kenya S, Okoro I, Wallace K, et al. Strategies to Improve HIV Testing in African Americans. The Journal of the Association of Nurses in AIDS Care : JANAC. 2015; 26: 357-67. PMid:26066691. https://doi.org/10.1016/j.jana.2015.04.001

[34] Rhodes SD, Malow RM, Jolly C. Community-based participatory research: a new and not-so-new approach to HIV/AIDS prevention, care, and treatment. AIDS education and prevention: official publication of the International Society for AIDS Education. 2010; 22: 173-83. PMid:20528127. https://doi .org/10.1521/aeap. 201 0.22 .3 .173

[35] Reif S, Safley D, McAllaster C, et al. State of HIV in the US Deep South. Journal of Community Health. 2017; 42: 844 53. PMid:28247067. https://doi.org/10.1007/s10900-017 $-0325-8$

[36] Raj A, Bowleg L. Heterosexual risk for HIV among black men in the United States: a call to action against a neglected crisis in black communities. American Journal of Men's Health. 2012; 6: 178-81. PMid:21831928. https://doi .org/10.1177/15579883114164 96 